2019-07-05

\title{
A cohort study of sustainability education in nursing
}

\author{
Warwick, Paul
}

http://hdl.handle.net/10026.1/14661

10.1108/IJSHE-02-2019-0064

International Journal of Sustainability in Higher Education

Emerald

All content in PEARL is protected by copyright law. Author manuscripts are made available in accordance with publisher policies. Please cite only the published version using the details provided on the item record or document. In the absence of an open licence (e.g. Creative Commons), permissions for further reuse of content should be sought from the publisher or author. 


\section{A cohort study of sustainability education in nursing}

Professor Janet Richardson, School of Nursing and Midwifery, Plymouth University, Drake Circus, Plymouth PL4 8AA, UK email: healthandplanet@gmail.com Daniel Clarke, School of Nursing and Midwifery, Plymouth University, Drake Circus, Plymouth PL4 8AA, UK email: Daniel.clarke@plymouth.ac.uk

Dr Jane Grose, School of Nursing and Midwifery, Plymouth University, Drake Circus, Plymouth PL4 8AA, UK email: jane.grose1@plymouth.ac.uk

Dr Paul Warwick, Centre for Sustainable Futures, Plymouth University, Drake Circus, Plymouth PL4 8AA, UK email: paul.warwick@plymouth.ac.uk

Submitted: 07-Feb-2019 and revised: 15-Apr-2019

\section{Abstract \\ Purpose}

The purpose of this study was to assess the contribution of scenario-based learning aimed at raising awareness of sustainability in healthcare practitioners. The Lancet Countdown on Climate Change calls for urgent action on health and climate change; this requires appropriate knowledge, skills and competencies that can be gained through undergraduate education. The International Council of Nurses calls for leadership in nursing for sustainability, however climate change and health are given little attention in nursing and healthcare curricula.

\section{Design}

A cohort of nursing and midwifery students were introduced to sustainability and climate change in the context of healthcare through scenario-based learning sessions in each of their three years of undergraduate education. Questionnaires were used to collect data on participant's attitudes toward sustainability and climate change, how useful the educational sessions were and the extent to which their clinical practice had changed.

Findings 
Significant differences were found between scores in year 1 and 2 suggesting greater awareness of the importance of sustainability in nursing education and practice. Comparisons of years 2 and 3 scores found participants more likely to apply sustainability principles in clinical practice, and challenge unsustainable practices in the work environment.

Implications

Further research is required to explore sustainability practice in postgraduate nurses I midwives. However this study supports the need for sustainability education to be embedded within healthcare professional degrees through applied and participatory pedagogical approaches.

Originality / value

As far as we are ware this is the first study to evaluate sustainability education and its impact on nursing attitudes towards practice.

\section{Key words}

Sustainability, climate change, healthcare, nursing, scenario-based learning, attitudes. 


\section{Introduction}

\section{Professional education: placing an active concern for well-being front and centre}

The health care sector has a clear contribution to make in achieving the United Nations Sustainable Development Goals, none more so than Goal 3 'Ensuring healthy lives and promoting the well-being for all at all ages'. But at the same time it is important to note that this sector is also a key contributor to global environmental challenges (WHO and HCWH, 2009) that are affecting the earth's essential support systems and, consequently, human health (McMichael, 2013; Ebi et al, 2017). Due to the healthcare sector's large carbon dioxide (CO2) emissions, immense water and food consumption, use of toxic materials and the production of vast amounts of waste, it can be seen to be contributing negatively to public health issues and damaging the ability of future generations to meet their own health needs (Anaker and Elf, 2014, WHO 2017).

Consequently, the Ostrava Declaration calls for the creation of more sustainable health systems. It recognizes that the UN's Global Goals highlight critical and inseparable links between development and the environment, between human wellbeing and the economy. This systems awareness in practice and policy is central to the attainment of a wide range of human rights including: the rights to life; the enjoyment of the highest attainable standard of physical and mental health (World Health Organization, 2017). This serves to highlight not only the manifold and interconnected nature of threats to public health but also the educational challenge of developing health service professionals who have an interdisciplinary and applied understanding of how to engage practically in addressing these threats.

Professionally tailored sustainability education is required for nursing and healthcare workers in order to help them acquire the knowledge, skills and values that empower them to contribute to the development of more sustainable health systems.

According to Anaker and Elf (2014) sustainability in nursing is conceptually linked to the ultimate goal of maintaining an environment that does not harm current and future generations. Based on the moral obligation to apply a health-in-all-policies approach (i.e. 'first do no harm') there is a pressing need for the health care sector to 
becomes more environmentally responsible and sustainable. The involvement of competent and well-informed nurses (and other health professionals) will be significant, and most likely crucial in facilitating this endeavour (Anaker and Elf, 2014). Furthermore, nurses and healthcare practitioners are in a good position to emphasise the health co-benefits of living more sustainably.

More specifically, the Lancet Countdown on Climate Change (Watts et al., 2017) calls for urgent action on health and climate change; the report provides evidence for increasing extreme weather events causing economic and health challenges, with a heavier burden on low income communities and those already disadvantaged.. Supply chains of important resources used in healthcare may be threatened by adverse weather events and the need to reduce fossil fuel use (Grose and Richardson, 2013a, 2013b). In addition, Leffers et al (2017) highlight the potential leadership role of nurses in addressing health and environmental issues and draw attention to the need for developing in them a range of sustainability and climate change competencies.

\section{Minding the gap: Sustainability competency development in nursing education}

There has been limited attention to the knowledge and competencies nurses will need in order to respond to global sustainability challenges; traditionally within higher education there has been an absence of climate change and sustainability topics in nursing (Goodman and Richardson, 2010; Goodman, 2011). However indications are that this is a growing area in healthcare professions (Schwerdtle et al., 2019; Walpole et al., 2019). Furthermore, some important insights can be gained from the wealth of global research into the more general field of Higher Education for Sustainable Development. Much of this has its roots in the monitoring and evaluation work instigated by the UN Decade on Education for Sustainable Development 20052014 (UNESCO 2014b)

Whilst still an emergent and contested field of educational practice, Education for Sustainable Development (ESD) research is revealing clear areas of commonality in the sustainability competencies that higher education is seeking to develop in graduates. For example, the review by Lozano et al (2017) offers a synthesis of common sustainability competencies to be a set of twelve including: systems 
thinking, interdisciplinary work, anticipatory thinking, justice, responsibility and ethics, critical thinking and analysis, interpersonal relations and collaboration, empathy and change of perspective, communication and use of media, strategic action, personal involvement, assessment and evaluation, and tolerance for ambiguity and uncertainty. Sterling et al (2017) note that where there is much more of a lack of attention within the ESD research is the specifics of how these competency objectives can be operationalised into pedagogical practice.

General guidance is increasingly being offered that supports the nurturing of these sustainability competencies through active, participatory and applied teaching and learning approaches (Leicht et al., 2018, UNESCO 2012, Tilbury 2011, QAA 2014, Peterson and Warwick 2015). This points towards the vital need for innovation and radical experimentation within Higher Education pedagogy; stretching beyond didactic information transmission structures and the confines of the campus. This supports the view of Fielding and Moss (2011) that what is required at this time is the enactment of pre-figurative educational practice in universities; innovations that are transitional, enabling significant aspects of the envisioned future educational provision to happen now, 'to build a new world in the shell of the old' (2011:149).

In support of this and within the specific field of nursing education, a curriculum development project has sought to embed pre-figurative practice in sustainability education within a UK University. Its specific focus has been on developing in nurses the core sustainability competency of systems thinking, realising the interconnections between their vocational goal of supporting healthy living and the global issue of climate change. The project adopted the definition of competency development provided by Glasser (2016):

A constellation of abilities attitudes, knowledge, understanding skills and habits of mind that are functionally linked to support both problem posing and problem solving and evoke purposeful behaviour toward particular end goals. (2016:126)

More specifically systems thinking was defined as the competency required to appreciate the interrelationships between environmental, social, economic, and 
political systems when trying to understand and professionally respond to sustainability challenges that exist at local and global levels.

The development of this competency was sought through the specific introduction of scenario-based learning within the nursing degree programme. Scenario-based learning draws from theories of situated learning and simulation, it is a methodology for getting students closer to the realities of their intended profession and its potential workplace challenges (Errington, 2010). This teaching approach was used to encourage systemic awareness by involving nurse students in real world nursing sustainability challenges and critical incidents through a descriptive set of circumstances where climate change could impact upon aspects of their practice. It invited the students to become more deeply aware of issues of sustainability, to explore interconnections and alternative practice outcomes and to identify potential nursing behaviour changes as discipline/professional based solutions (Bessant, 2013).

This pre-figurative practice built upon recent work to introduce sustainability and climate change in nursing education (Grose and Richardson 2015). In particular, it responds to Richardson et al. (2017) drawing attention to the need to develop innovative applied pedagogic approaches whilst threading a challenging topic throughout the undergraduate curriculum. This engages student nurses in a sustainability topic for which they may not easily see the relevance of to their professional practice. Exploring practically the potential of pedagogical approaches such as scenario-based learning responds directly to the proposal of Weeks et al (2017) that advances in clinical simulation can enhance cognitive, functional and ethical competence in nursing education; thus future-proofing nurses for a constantly changing and uncertain world.

\section{Research into a scenario-based learning approach to Sustainability in Nursing Education}

The aim of this study was to measure the attitudes of student nurses and midwives towards climate change and sustainability and the inclusion of these topics in nurse education. Previous studies (Richardson et al 2017) assessed attitudes before and 
after the delivery of one specific sustainability scenario-based learning session when delivered to $2^{\text {nd }}$ year nursing and midwifery students. Richardson et al (2017) found that attitudes and knowledge improved immediately following participation in the session, demonstrating immediate learning. However, this does not provide evidence for sustained attitude change and how this translates into practice. Therefore, in this study, we wanted to explore the extent to which participants' attitudes changed over time, and if any associated learning was still apparent toward the end of the students' three-year course. Additionally, we were keen to determine if the applied scenario-based learning approach was useful for engaging student nurses and midwives in making a positive change within their own professional practice.

\section{Methods}

A cohort study was designed to assess nurse and midwifery students' attitudes towards sustainability and climate change over the course of their three-year academic programme. At the University of Plymouth (UK) student nurses and midwives are exposed to issues regarding climate change and sustainability throughout their academic studies. A number of modules, for example public health, include the potential for changing patterns of disease as a consequence of climate change, management modules include the management of resources and how these might be impacted on as a consequence of flooding or drought. Additionally, the students participate in sessions specifically designed to raise awareness about sustainability, climate change and health in each year of their three-year Degree course. The content of these sessions is evidence-based, providing examples of the global consequences of climate change on health, and includes mitigation and adaptation approaches. All the teaching materials are available in the NurSusTOOLKIT (www.nursus.eu).

Year one sustainability-specific session: This first session introduces climate change and health to the nursing and midwifery students in their 'induction' period. This is their first week in the University when they participate in sessions designed to introduce them to nursing and the University. The session takes the form of a case study scenario of a family, (a pregnant mother of a small child with asthma) where their care is compromised by problems due to climate change or sustainability 
challenges, for example resources scarcity. This includes a situation where the small child has an exacerbation of his asthma due to excessive air pollution. A further situation is encountered when an extreme weather event leads to the family being rescued from a flooded home, resulting in the pregnant women sustaining a head injury and requiring intensive care that is also compromised because of problems with supplies due to an earthquake at the factory site. The case study is simulated, however all the examples within it are based on previous events or evidence of potential climate change effects and resource supply challenges.

In the second year, the students engaged in a scenario-based session alongside clinical skills practice. This session is based on evidence from research regarding the potential interuption to supply of important healthcare products (Grose and Richardson 2013a, 2013b). It has been delivered to over 600 students (see this short film by way of example http://youtu.be/zIFT2Dbg080) and results demonstrated significant changes in knowledge and attitudes toward sustainablity and climate change following the session Richardson et al (2017). The session encourged the students to make connections between the items they use in clinical practice on a daily basis and the fact that many of these items are made from potentially scarce natural resources (such as oil and cotton). Students discussed procurement and waste management; they considered the importance of specific clinical items in healthcare, what they would do if the natural resources they are made from were no longer available and how they might plan future care using alternatives.

In year three the students were presented with the scenario of a patient manifesting specific symptoms that ultimately relate to an outbreak of Escherichia coli (E.coli). Links are made to the potential for an increase in the spread of waterborne disease and the introduction of new disease patterns due to climate change. Students participated in an activity that required them to design a programme to manage the outbreak, including dealing with attention from newspaper journalists and developing a wider public health awareness campaign. Following the activity they reflected on how climate change and associated environmental damage (such as flooding and soil degradation) can impact on health.

\section{Sample}


Student nurses and midwives commencing their undergraduate degree at the University of Plymouth in September 2014 were invited to take part in this research project to investigate the impact of the scenario-based learning approach. Students consented to participate in the project and agreed to complete the SANS survey on three occasions. Students' names were required on the survey in order that they could be matched to surveys completed in subsequent years, however individual students were not identifiable in the data analysis. Surveys were completed on three occasions (i) at the start of academic year 1, prior to any exposure in the course to sustainability and climate change; (ii) in year 2 , following the sustainability scenario session detailed above; (iii) in year 3, following the sustainability scenario session detailed above. Ethical approval for the study was provided by the relevant research ethics committee of the University of Plymouth.

\section{Use of the Sustainability Attitudes in Nursing Survey (SANS)}

The 'Sustainability Attitudes in Nursing Survey' (SANS) questionnaire used in this study was initially developed and piloted at University of Plymouth (UK) in order to assess the impact of sustainability awareness sessions on second year student nurses. The questionnaire was based on discussions with experts from nursing education, and questions seek agreement or disagreement with statements regarding climate change and sustainability. This 7-item SANS questionnaire was translated and piloted with 363 nursing students in three universities (one each in Germany, Spain and UK). Psychometric analyses were performed for the whole sample and for the individual countries. Item inter-correlations were all positive and highly significant and ranged from .28 to .80 . Reliability Analysis revealed a Cronbach's alpha of .86. All psychometric analyses were repeated for data from each country revealing results that were comparable to the results found in the total sample. Further analyses revealed that dropping specific items would not result in reduced internal consistency, therefore the SANS questionnaire was revised so that SANS_2 focuses on 5 Likert scale items. The SANS_2 version of the questionnaire was translated into French, Spanish and German in order to evaluate the attitudes of student nurses in a number of Schools of Nursing in Europe (Richardson et al. 
2016a). The SANS_2 questionnaire has also been adapted for use with paramedic students (Richardson et al., 2016b),

The SANS questionnaire used in this research contains the 5 Likert scale items from the SANS_2. Further items (items 6-9) were included in the survey for this current study for students in years 2 and 3 in order to investigate sustainability awareness in nursing practice (see Box 1). Responses were required on a 7-point scale where 1 was 'strongly disagree', and 7 was 'strongly agree'.

Box 1 Sustainability Attitudes in Nursing Survey items
1. Climate change is an important issue for nursing / healthcare
2. Issues about climate change should be included in the nursing / midwifery curriculum
3. Sustainability is an important issue for nursing / midwifery
4. Sustainability should be included in the nursing / midwifery curriculum
5. I apply sustainability principles at home
6. I apply sustainability principles in my nursing / midwifery practice
7. I am aware of unsustainable practice in my work environment
8. I challenge unsustainable practice in my work environment
9. I feel unable to challenge unsustainable practice in my work environment

Students were also asked questions related to the usefulness of the teaching sessions and the scenarios presented to examine the perceived reality and relevance of the pedagogical approach and content (box 2). Responses were required on a 7-point scale where 1 was 'strongly disagree', and 7 was 'strongly agree'.

Box 2 Questions regarding feedback on the sustainability scenario-based sessions
10. The scenario was realistic
11. The resources were useful
12. The session was interesting
13. The session was engaging
14. The session helped me to make links between climate change and health
15. I enjoyed the session
16. The session helped me to make links between resources and heath 17. I would prefer this session as a lecture 
Data were entered into SPSS version 21 for analysis. Kolmogorov Smirnov test for distribution for all variables was significant $(p=0.000)$ indicating non-normal distribution. For surveys completed in years 1 and 2, items $1-5$ were compared; all items were compared for surveys completed in year 2 and 3. Related sample Wilcoxon Signed Rank tests were used to test for differences in scores for different years. Measures of central tendency were computed and means reported in order to determine the direction of any significant differences in the results. Descriptive analysis was undertaken for the questionnaire items that required feedback on the teaching sessions and asked about the usefulness of the scenario-based approach (statements in box 2) in years 2 and 3.

\section{Results}

Two hundred and forty six questionnaires were returned in both years 1 and 2, and 145 in year 3. Median scores for all participants are reported in Table 1.

Table 1. Median scores for all participants (note that these are not matched pairs and only statements $1-5$ apply to year 1 )

\begin{tabular}{|c|c|c|c|}
\hline Statement & \begin{tabular}{|l|} 
Year 1 \\
$(\mathrm{~N}=246)$ \\
median
\end{tabular} & $\begin{array}{l}\text { Year } 2 \\
(\mathrm{~N}=246) \\
\text { median }\end{array}$ & $\begin{array}{l}\text { Year } 3 \\
(\mathrm{~N}=145) \\
\text { median }\end{array}$ \\
\hline $\begin{array}{l}\text { 1. Climate change is important for nursing } \\
\text { healthcare }\end{array}$ & 5.0 & 6.0 & 6.0 \\
\hline $\begin{array}{l}\text { 2. Issues about climate change should be } \\
\text { included in the nursing / midwifery } \\
\text { curriculum }\end{array}$ & 4.0 & 6.0 & 6.0 \\
\hline $\begin{array}{l}\text { 3. Sustainability is an important issue for } \\
\text { nursing / midwifery }\end{array}$ & 5.0 & 7.0 & 7.0 \\
\hline $\begin{array}{l}\text { 4. Sustainability should be included in the } \\
\text { nursing / midwifery curriculum }\end{array}$ & 5.0 & 7.0 & 7.0 \\
\hline 5. I apply sustainability principles at home & 5.0 & 5.0 & 6.0 \\
\hline $\begin{array}{l}\text { 6. I apply sustainability principles in my } \\
\text { nursing / midwifery practice }\end{array}$ & NA & 5.0 & 6.0 \\
\hline $\begin{array}{l}\text { 7. I am aware of unsustainable practice in } \\
\text { work environment }\end{array}$ & NA & 6.0 & 6.0 \\
\hline $\begin{array}{l}\text { 8. I challenge unsustainable practice in } \\
\text { work environment }\end{array}$ & NA & 4.0 & 5.0 \\
\hline
\end{tabular}




\begin{tabular}{|l|l|l|l|}
\hline & & & \\
\hline $\begin{array}{l}\text { 9. I feel unable to challenge } \\
\text { unsustainable practice in work } \\
\text { environment }\end{array}$ & NA & 5.0 & 5.0 \\
\hline
\end{tabular}

Returned questionnaires were matched to ensure that the same participants were being compared across the three years of their nurse education course. A total of 246 questionnaire matched pairs were compared for years 1 and 2; 145 pairs were compared for years 2 and 3.

Significant differences were found between year 1 and year 2 scores on

(1) Climate change is important for nursing / healthcare $(p=0.000)$;

(2) Issues about climate change should be included in the nursing / midwifery curriculum $(p=0,000)$;

(3) Sustainability is an important issue for nursing / midwifery $(p=0.000)$;

(4) Sustainability should be included in the nursing / midwifery curriculum $(p=0.000)$;

(5) I apply sustainability principles at home $(p=0.000)$.

Measures of central tendency indicated that the change was in the direction of higher scores (more agreement with the statements) in year 2 (table 2).

Table 2. Comparisons of statements between year 1 and year 2 (means and standard deviations for matched pairs) * indicates significant difference

\begin{tabular}{|l|l|l|}
\hline Statement & $\begin{array}{l}\text { Year 1 } \\
\text { mean (SD) }\end{array}$ & $\begin{array}{l}\text { Year 2 } \\
\text { mean (SD) }\end{array}$ \\
\hline $\begin{array}{l}\text { 1. Climate change is important for nursing } \\
\text { healthcare }\end{array}$ & $4.64(1.39)$ & $6.49^{*}(0.89)$ \\
\hline $\begin{array}{l}\text { 2. Issues about climate change should be } \\
\text { included in the nursing / midwifery curriculum }\end{array}$ & $4.13(1.39)$ & $6.09^{*}(0.99)$ \\
\hline $\begin{array}{l}\text { 3. Sustainability is an important issue for nursing } \\
\text { / midwifery }\end{array}$ & $5.22(1.30)$ & $6.49^{*}(0.78)$ \\
\hline $\begin{array}{l}\text { 4. Sustainability should be included in the nursing } \\
\text { / midwifery curriculum }\end{array}$ & $4.85(1.40)$ & $6.31^{*}(0.90)$ \\
\hline 5. I apply sustainability principles at home & $4.82(1.32)$ & $5.19^{*}(1.12)$ \\
\hline
\end{tabular}


Significant differences were found between year 2 and year 3 scores on (3) Sustainability is an important issue for nursing / midwifery ( $p=0.004)$; (5) I apply sustainability principles at home $(p=0.03)$. Mean scores indicate that the change was in the direction of higher scores (more agreement with the statements) in year 2 than in year 3 (table 3 ).

Table 3. Comparisons of statements between year 2 and year 3 (means and standard deviations for matched pairs) * indicates significant difference

\begin{tabular}{|l|l|l|}
\hline Statement & $\begin{array}{l}\text { Year 2 } \\
\text { mean (SD) }\end{array}$ & $\begin{array}{l}\text { Year 3 } \\
\text { mean (SD) }\end{array}$ \\
\hline $\begin{array}{l}\text { 1. Climate change is important for nursing } \\
\text { healthcare }\end{array}$ & $6.23(0.89)$ & $6.11(0.97)$ \\
\hline $\begin{array}{l}\text { 2. Issues about climate change should be } \\
\text { included in the nursing / midwifery curriculum }\end{array}$ & $6.10(0.99)$ & $5.92(1.10)$ \\
\hline $\begin{array}{l}\text { 3. Sustainability is an important issue for nursing } \\
\text { / midwifery }\end{array}$ & $6.57(0.63)$ & $6.36^{*}(0.88)$ \\
\hline $\begin{array}{l}\text { 4. Sustainability should be included in the nursing } \\
\text { / midwifery curriculum }\end{array}$ & $6.33(0.82)$ & $6.19(1.00)$ \\
\hline $\begin{array}{l}\text { 5. I apply sustainability principles at home } \\
\text { 6. I apply sustainability principles in my nursing / } \\
\text { midwifery practice }\end{array}$ & $5.24(1.12)$ & $5.41^{*}(1.10)$ \\
\hline $\begin{array}{l}\text { 7. I am aware of unsustainable practice in work } \\
\text { environment }\end{array}$ & $5.86(0.95)$ & $5.54^{*}(0.98)$ \\
\hline $\begin{array}{l}\text { 8. I challenge unsustainable practice in work } \\
\text { environment }\end{array}$ & $3.93(1.34)$ & $4.38^{*}(1.30)$ \\
\hline $\begin{array}{l}\text { 9. I feel unable to challenge unsustainable } \\
\text { practice in work environment }\end{array}$ & $4.78(1.40)$ & $4.43^{*}(1.41)$ \\
\hline
\end{tabular}

Comparisons of years 2 and 3 scores found significant differences between scores for item (6) I apply sustainability principles in my nursing / midwifery practice $(p=0.000)$, and (8) I challenge unsustainable practice in my work environment $(p=0.001)$. Mean scores for this item indicated that the change was in the direction of 
higher scores (more agreement with the statements) in year 3. For item (9) I feel unable to challenge unsustainable practice in my work environment $(p=0.006)$, mean scores indicated less agreement in year 3 than year 2 (table 4 ).

Table 4. Scores above 5 on session feedback sessions (based on Likert scale where 1 = strongly disagree and 7 = strongly agree)

\begin{tabular}{|l|c|c|}
\hline Questionnaire statement & $\begin{array}{c}\text { Frequency } \\
\text { scoring higher } \\
\text { than 5 (year 2) }\end{array}$ & $\begin{array}{c}\text { Frequency } \\
\text { scoring higher } \\
\text { than 5 (year 3) }\end{array}$ \\
\hline 10. The scenario was realistic & $95 \%$ & $89 \%$ \\
\hline 11. The resources were useful & $97 \%$ & $85 \%$ \\
\hline 12. The session was interesting & $95 \%$ & $88 \%$ \\
\hline 13. The session was engaging & $98 \%$ & $90 \%$ \\
\hline $\begin{array}{l}\text { 14. The session helped me to make links between } \\
\text { climate change and health }\end{array}$ & $96 \%$ & $90 \%$ \\
\hline $\begin{array}{l}\text { 15. I enjoyed the session } \\
\text { 16. The session helped me to make links between } \\
\text { resources and heath }\end{array}$ & $98 \%$ & $\mathbf{8 4 \%}$ \\
\hline 17. I would prefer this session as a lecture & $98 \%$ & $\mathbf{8 7 \%}$ \\
\hline
\end{tabular}

Feedback on the relevance and usefulness of the scenario-based approach showed more than $95 \%$ of participants rated the sessions positively in year 2 and more than $84 \%$ rated the year 3 session positively (scoring more than 5 on the 7-point scale). For the statement 'I would prefer this session as a lecture' only $24 \%$ (year 2), and $25 \%$ (year 3 ) were in agreement (scoring more than 5 on the 7-point scale).

\section{Discussion}

The findings from this research project highlight that a number of Lozano et al's (2017) common sustainability competencies are being developed through the scenario-based learning pedagogical approach. Although the key interest of our study has been to better understand the acceptance of systems thinking and its value in relating the professional practice of nurses to their impact on the environment, other issues appeared to have value. For example in making the links 
between resources and health the students had been engaged in 'justice responsibility and ethics, critical thinking and analysis'; the group work sessions engaged them in discussion, allowing 'interpersonal relations and collaboration, empathy and change of perspective', which the majority preferred.

Our findings indicate that teaching sustainability in general and engaging student nurses and midwives with the sustainable development goal of climate action in particular can change participants' attitudes toward these subjects. Furthermore, the feedback on the scenario-based pedagogical approach was positive; students found the sessions interesting, engaging and enjoyable. In particular, the resources used in the sessions were viewed as useful, helping the students to make links between climate change, resources used within health care and public health. The scenarios were thought to be realistic. Despite students' overriding preference for this applied and active pedagogical approach it is important to note that not all students had this view. Instead a quarter of participants expressed a preference for the more traditional and didactic form of instruction through lectures. This highlights that when research-informed innovation in teaching practice is implemented within existing institutional structures, not all students will appreciate this change to the status quo or report satisfaction and benefit. Research highlights that within the process of educational change resistance from key stakeholders is commonplace (Fullan 2005, 2015). Our research indicates some degree of resistance from the very students whose learning we were seeking to improve; twenty five percent of participants reported that they would prefer receiving this material in the form of a lecture. The NurSusTOOLKIT responds to the need for different methods of delivering the challenging subject of climate change and health by providing didactic materials (powerpoint lectures) as well as group exercises, discussions points, and additional reading.

The significant differences between scores on the items 'I challenge unsustainable practice in my work environment $(p=0.001)$ ' showing greater agreement in year 3 than year 2; and 'I feel unable to challenge unsustainable practice in my work environment' (greater agreement in year 2 than year 3) are important to note. Students with greater experience and maturity are likely to have more confidence in their own knowledge and ability, and therefore may be more willing to challenge 
unsustainable practice. This finding indicates the potential of this educational approach to develop more 'sustainability confident' healthcare practitioners who are able to take their learning into practice and make a difference to the environment in which they work. Arguably students develop confidence during their education and feel more able to challenge practice as they progress from beginner to qualified practitioner and our results may be an artefact of this. However, student confidence to challenge practice with respect to climate change and sustainability is unlikely to develop in the absence of specific education about the topics. Some of the effects seem to be stronger between years 1 and 2 than years 2 and 3 , for example attitudes towards the importance of sustainability and climate change for nursing and midwifery. Conceivably the attitude change could relate to the initial introduction to the relevance of these topics to healthcare; the challenge is then to translate this attitude change into practice, supported by increased knowledge and confidence.

We acknowledge that a limitation of this study is the lack of a comparison (control) group with which to compare students who had the educational interventions. Our curriculum was developed in order to include sustainability for all nursing and midwifery students based on feedback from earlier research; associated questions were included in student assessment therefore it would have been unethical to withhold the sustainability sessions from some students. However future research, possibly in other universities where the topic is not already included in the curriculum, could include a control group, and this would certainly help to further investigate the extent of impact from ESD interventions in this specific area.

\section{Implications for Future Practice}

The International Council of Nurses position statement (ICN, 2018) draws attention to the powerful contribution nurses can make to mitigating climate change and supporting communities to adapt to the health consequences. The ICN (2018) calls for nurse 'leadership from nurses to take immediate action to build climate resilient health systems' ( 1 1). In order to take action, nurses need to be equipped with relevant information; topics regarding sustainability and climate change need to be embedded in nursing education using pedagogic approaches that are engaging and facilitate learning and attitude change. 
This research project has been part of a wider collaboration of nursing education practitioners across Europe. Its contribution highlights the potential value of an active, participatory and applied pedagogical approach, and in particular the significance of student engagement that can be made by scenario-based learning. The NurSusTOOLKIT (www.nursus.eu) site makes available all the different case study scenario teaching and learning materials alongside more general guidance for nurse and healthcare practitioner educators in how to best integrate sustainability into their teaching practice. The NurSus site could also serve as a conduit for further research to be developed and disseminated - in particular investigating more deeply the development of sustainability competencies in other healthcare professionals.

This teaching approach and the NurSusTOOLKIT materials have wider application to other professionals beyond healthcare. For example the work with 3D design students at the University of Plymouth, as part of their sustainable materials module has been recognised by a green gown award in 2014 (http://youtu.be/zIFT2Dbg080). Other areas are seeing the relevance of this approach for example working with business students on resource management and supply chain challenges of climate change (Mukonoweshuro; et al 2018). These teaching materials are relevant for learning objectives for sustainability education that could be shared across health disciplines. Walpole et al (2019), for example, outline sustainable healthcare learning outcomes that, although developed in medicine, are applicable across all healthcare professionals and health systems. Furthermore the materials are consistent with and support the World Health Organization (2015) operational framework for building climate resilient health systems.

The SANS questionnaire has been well tested and provides a snapshot of changes in attitudes and the relevance of scenario-based education to nursing. What is needed now is a follow up study to examine practice-focussed interventions implemented as a consequence of sustainability in nurse education. This could be achieved by qualitative interviews or an observation study. This in-depth evaluation was conducted in one school of nursing. It would be valuable to encourage other schools to adopt similar approaches to sustainability education so that further evaluation of change would enhance and confirm our findings. Other pedagogic approaches for teaching sustainability to healthcare professionals have been suggested and could be evaluated (Schwerdtle et al., 2019) A review of how other 
nurse educators have approached this subject would also be beneficial in order to compare and contrast attitudes toward climate change and health across the sector..

\section{Conclusion}

The development of knowledge and attitudes are key elements within the constellation of a competence; currently there is limited attention given to nursing competences in relation to sustainability and climate change (Leffers et al., 2017). The sustainability competency of 'systems thinking' is very relevant in the context of nursing and healthcare; helping healthcare practitioners to understand the connections between their actions in delivering healthcare and the impact on the environment. This awareness is a key foundation upon which nurses can then build when making positive changes in practice toward greater sustainability.

The literature on Education for Sustainable Development highlights the need for innovative pedagogical approaches when seeking to develop, in graduates, competencies such as systems thinking. Topics such as climate change and sustainability will only be successfully embedded into nursing and healthcare professional education if they are seen to have practical and professional relevance. This curriculum innovation and research project has highlighted the use of real and applied clinical scenarios that make links to climate events and threats to resources used in everyday clinical practice; it can significantly change attitudes and highlight the relevance of these topics in healthcare.

Using a scenario-based learning approach with practical and relevant case studies has a wider applicability to other professional degree programmes. Such an approach can provide not only a professionally specific pathway to engagement but crucially we believe will help to point towards the pressing need for professionals to also be engaged in interdisciplinary scenario-based learning. This is where we more effectively collapse the siloed walls of our current professional higher education programmes and graduates learn to translate and apply their areas of expertise alongside those of different professional training, in order to engage with a much more joined up and integrated approach to creating more sustainable futures that serve the well-being of all. 


\section{REFERENCES}

Anna A and Elf M (2014) Sustainability in nursing: a concept analysis. Scandinavian Journal of caring sciences Scand J Caring Sci; 28; 381-389

Bessant, S., Bailey, P., Robinson, Z., Ormerod, M. Tomkinson, C., Tomkinson R. and Boast, R. (2013) Problem-Based Learning: A case study of sustainability education. Keele University.

Ebi, K.L., Frumkin H., Hess J.J. (2017) Protecting and promoting population health in the context of climate and other global environmental changes. Anthropocene 19:112

Errington, E. (Ed) (2010) Preparing graduates for the professions using scenariobased learning. Brisbane, Post Pressed.

Fitzpatrick, J. (2010) The impact of healthcare on the environment: improving sustainability in the health service. The Nursing Times 106:8

Fullan, M. (2015) The New Meaning of Educational Change. London: Routledge.

Fullan, M. (2005) Leadership and Sustainability: Systems Thinkers in Action. California: Corwin Press.

Glasser, H. (2016) 'Toward the development of robust learning for sustainability core competencies'. Sustainability. Vol.9, No.3 pp121-134

Goodman B and Richardson J. (2010) Climate Change, Sustainability and Health in UK Higher Education: The Challenges for Nursing pp109 - 131. In: Jones P., Selby D., Sterling S. Sustainability Education: Perspectives and Practice Across Higher Education. London, Earthscan

Goodman, B. (2011). The need for a 'sustainability curriculum' in nurse education. Nurse Education Today 31(8):733-7. 
Goodman, B., East, L., (2014). The 'sustainability lens': a framework for nurse education that is 'fit for the future'. Nurse Education Today 34(1):100-3. doi:10.1016/j.nedt.2013.02.010.

Grose J and Richardson J. (2015) Can a sustainability and health scenario provide a realistic challenge to student nurses and lead to a commitment to making changes in practice? Nursing and Health Sciences (2):256-61

Grose, J and Richardson, J. (2013a) "Managing a sustainable, low carbon supply chain in the English National Health Service: The views of senior managers", Journal of Health Services Research \& Policy, 18(2): 83-89

Grose J and Richardson J. (2013b) Strategies to identify future shortages due to interruptions in the healthcare procurement supply chain: a method from the English National Health Service. Journal of Health Service Research Policy and Practice. 19/1(19-26): 1355-8196

International Council of Nursing (2018) Nurses Climate Change and Health https://www.icn.ch/sites/default/files/inline-

files/ICN $\% 20$ PS $\% 20$ Nurses $\% 252$ c\%20climate $\% 20$ change $\% 20$ and $\% 20$ health $\% 20 \mathrm{FI}$ NAL\%20.pdf Accessed 22/11/2018

Leicht, A., Heiss, J. and Byun, J. (Eds) (2018) Issues and trends in Education for Sustainable Development. Paris, UNESCO.

Leffers, J., McDermott, R., Nichols P.K., Sweeney, C.F. (2017) Mandate for the Nursing Profession to Address Climate Change Through Nursing Education. The Journal of Nursing Scholarship 49(6): 679-687

Lozano, R., Merrill, M., Sammalisto, K., Ceulemans, K. \& Lozano, F.J. (2017) 'Connecting competencies and pedagogical approaches for sustainable development in higher education: A literature review and framework proposal.' Sustainability 9: 1-15. 
McMichael A. J. (2013) Globalization, Climate Change, and Human Health. New England Journal of Medicine 368:1335-1343

Mukonoweshuro, R., Richardson, J., Grose, J., Tauringana, V., Suchanging, C. (2018) Accounting undergraduates' attitudes towards sustainability and climate change through using a sustainability scenario-based intervention within curriculum to enhance employability attributes. International journal of business research. 18(4): 8190.

Peterson, A. and Warwick, P. (2015) Global Learning and Education. Oxon: Routledge.

Quality Assurance Agency (2014) Education for sustainable development: guidance for UK higher education providers. Gloucester, QAA.

Richardson, J., Grose, J., Bradbury, M., Kelsey, J. (2017) Developing awareness of sustainability in nursing and midwifery using a scenario-based approach: Evidence from a pre and post educational intervention study. Nurse Education Today 54:51-55

Richardson, J., Grose, J., Doman, M., Kelsey, J. (2014) The use of evidenceinformed sustainability scenarios in the nursing curriculum: development and evaluation of teaching methods. Nurse Education Today. 34:490-93

Richardson J, Heidenreich T, Álvarez-Nieto C, Fasseur F, Grose J, Huss N, Huynen M, López-Medina I, Schweizer A. (2016a) Including sustainability issues in nurse education: a comparative study of first year student nurses' attitudes in four European countries. Nurse Education Today 37:15-20

Richardson, J., Grose J., Allum, P. (2016b) Can a health and sustainability scenario session change undergraduate paramedic students' attitudes towards sustainability and climate change? Journal of Paramedic Practice 8(3):130-136 
Richardson J., Grose J., Bradbury M., Kelsey J. (2017) Developing awareness of sustainability in nursing and midwifery using a scenario-based approach: Evidence from a pre and post educational intervention study. Nurse Education Today 54:51-55

Counting down to climate change (Editorial) (2016) The Lancet 390:10107

Schwerdtle, P.N., Maxwell, J., Norton, G., Bonnamy, J., 201912 tips for teaching environmental sustainability to healthcare practitioners. Medical Teacher DOI: 10.1080/0142159X.2018.1551994

Sterling, S., Glasser, H., Rieckmann, M. and Warwick, P. (2017) 'More than scaling up: a critical and practice inquiry into operationalising sustainability competencies' in Blaze Corcoran P., Weakland, J. Wals A (Eds) Envisioning futures for environmental and sustainability education. Wageningen: Wageningen Academic Publishers.

Tilbury, D. (2011) Education for sustainable development: an expert review of processes and learning. Paris: UNESCO.

UNESCO (2012) Shaping the education of tomorrow:2012 report on the UN decade of education for sustainable development. Paris: UNESCO

UNESCO (2014a) Roadmap for Implementing the Global Action Programme on Education Development. Paris: UNESCO. Available at http://unesdoc.unesco.org/images/0023/002305/230514e.pdf.

UNESCO (2014b). Shaping the future we want. UN Decade of Education for Sustainable Development (2005-2014) Final Report. Paris: UNESCO.

United Nations (2015) Resolution adopted by the General Assembly on 25 September 2015. Transforming our world: the 2030 agenda for sustainable development. Available at http://www.un.org/ga/search/view_doc.asp?symbol=A/RES/70/1\&Lang=E.

Walpole, S.C., Barna, S., Richardson, J., Rother H.A. (2019) Sustainable healthcare education: integrating planetary health into clinical education. The Lancet Planetary Health. Vol 3: e6-e7 
Watts N. et al (2017) The Lancet Countdown on health and climate change: from 25 years of inaction to a global transformation for public health. The Lancet http://www.thelancet.com/pdfs/journals/lancet/PIIS0140-6736(17)32464-9.pdf (Accessed 13/12/2017)

World Health Organization. Declaration of the Sixth Ministerial Conference on Environment and Health 15 June 2017 http://www.euro.who.int/en/mediacentre/events/events/2017/06/sixth-ministerial-conference-on-environment-andhealth/documentation/declaration-of-the-sixth-ministerial-conference-onenvironment-and-health accessed $23^{\text {rd }}$ October 2018

World Health Organization Operational framework for building climate resilient health systems 2015 https://www.who.int/globalchange/publications/building-climateresilient-health-systems/en// (accessed 5/4/2019)

Weeks, K., Coben, D., Lum G., Pontin D. (2017) Developing nursing competence: Future proofing nurses for the changing practice requirements of $21^{\text {st }}$ century healthcare. Nurse Education in Practice. 27: A3-A4 http://dx.doi.org/10.1016/j.nepr.2017.08.020

The authors

Professor Janet Richardson (Emeritus Professor) is a registered nurse and psychologist specialising in education for sustainability in health care and well-being. She has been the recipient of a number of awards for her work on embedding sustainability in the healthcare curricula, for example a Green Gown Award in the 2014 courses and learning category. She led a multi-disciplinary team working on health and sustainability education funded by an EU project grant during $2013-18$. Her current research and practice engages healthcare providers and students to find solutions to the challenges that climate change and resource depletion present for health and healthcare delivery.

Daniel Clarke (Lecturer in Nursing) has recently moved from nursing clinical practice into education and research. His background is in the military (Royal Engineers) and the Emergency Department. Working at the University of Plymouth for the past 2 
years, his current interests are in sustainability and student assessment in practice. As a late entrant to nursing, he brings a long-standing interest in sustainability and the potential applications to clinical practice. In his teaching sessions, he encourages students to reflect on how they can be more sustainable in their nursing practice as well as in their personal lives.

Dr Jane Grose (Honorary Research Fellow) has worked in health and health service delivery nationally and internationally for over 40 years. Initially focusing on international development especially around HIVIAIDS she developed training to help support and inform young people. In the last 15 she has used qualitative research to understand how people with long term conditions access psychosocial support. More recently she has been part of a specialist team and used her skills to add to our knowledge about people's attitudes and behaviours relating to climate change and the management of resources in health care.

Paul Warwick has worked in the field of educational innovation for the last 20 years. He currently serves as Associate Professor in Sustainability and Civic Education and leads the Centre for Sustainable Futures at the University of Plymouth. This role involves working with staff and students to catalyse sustainable education within the curriculum and the broader student experience of Higher Education. He has authored a wide range of academic publications, including co-authoring the book Global Learning and Education (Routledge 2015). His research interests encompass student voice, service learning, experiential education and compassionate processes for educational change. 